\title{
Mutations of the SPG11 gene in patients with autosomal recessive spastic paraparesis and thin corpus callosum
}

M-J Lee, T-W Cheng, M-S Hua, M-K Pan, J Wang, D A Stephenson and C-C Yang

J. Neurol. Neurosurg. Psychiatry 2008;79;607-609

doi:10.1136/jnnp.2007.136390

Updated information and services can be found at:

http://jnnp.bmj.com/cgi/content/full/79/5/607

\section{These include:}

References This article cites 6 articles, 2 of which can be accessed free at: http://jnnp.bmj.com/cgi/content/full/79/5/607\#BIBL

1 online articles that cite this article can be accessed at:

http://jnnp.bmj.com/cgi/content/full/79/5/607\#otherarticles

Rapid responses $\quad \begin{aligned} & \text { You can respond to this article at: } \\ & \text { http://jnnp.bmj.com/cgi/eletter-submit/79/5/607 }\end{aligned}$

Email alerting Receive free email alerts when new articles cite this article - sign up in the box at service the top right corner of the article

Notes

To order reprints of this article go to:

http://journals.bmj.com/cgi/reprintform

To subscribe to Journal of Neurology, Neurosurgery, and Psychiatry go to:

http://journals.bmj.com/subscriptions/ 
autosomal-dominant HSP, which is higher than the estimated $40 \%$ linked to this locus. ${ }^{3}$ A possible explanation for the higher rate of SPG4 families and previously reported mutations in our dataset might be attributable to common founders in Eastern Europe or mutational hot-spots in the SPG4 gene.

The missense mutation Pro365Arg falls within the highly conserved AAA cassette of spastin. At this position, an amino acid with a negative charge is conserved among spastin homologous proteins, including in Pan troglodytes, Mus musculus, Gallus gallus and Drosophila melanogaster. The missense mutation Asp542Gly falls within the highly conserved AAA domain of the protein, like most of the known mutations that we identified (table 1). The corresponding amino acid is well conserved in the species described above (alignment of spastin homologous proteins is available on request). The deletion mutation 1352_1356delGAGAA results in a frame-shift mutation at position 452, leading to a premature stop codon at position 456 and to a truncated protein, which is probably insufficient for self-assembly or might be degraded by the proteosome pathway.

Our finding of a higher rate of mutations in affected individuals with an autosomaldominant trait inheritance and late onset of the disease needs to be validated in a larger dataset; nevertheless, it indicates that SPG4 mutation screening is strongly recommended in patients with this form of the disease and mutations in other genes are rare causes of autosomal-dominant HSP. Finally, these findings might facilitate better application of diagnostic tests in HSP and provide new insights into the clinical aspects and molecular basis of SPG4-HSP.

\section{A Orlacchio, ${ }^{1,2}$ C Patrono, ${ }^{1}$ A Borreca, ${ }^{1,2}$ C Babalini, ${ }^{1}$ G Bernardi, ${ }^{1,2}$ T Kawarai ${ }^{3}$}

1 Laboratorio di Neurogenetica, CERC-IRCCS Santa Lucia, Rome, Italy; ${ }^{2}$ Dipartimento di Neuroscienze, Università di Roma "Tor Vergata", Rome, Italy; ${ }^{3}$ Department of Neurology, Hyogo Brain and Heart Center, Himeji City, Japan

Correspondence to: Dr Antonio Orlacchio, Laboratorio di Neurogenetica, Centro Europeo di Ricerca sul Cervello (CERC) - Istituto di Ricovero e Cura a Carattere Scientifico (IRCCS) Santa Lucia, 64 Via del Fosso di Fiorano, Rome 00143, Italy; a.orlacchio@hsantalucia.it

Acknowledgements: We thank the patients and family members involved in this study. We thank Hilary Giles (MA) for her language advice and assistance, and members of our laboratories for stimulating discussions and helpful comments on this manuscript. We are extremely grateful to the Genetic Bank of the Laboratorio di Neurogenetica, Centro Europeo del Cervello-Istituto di Ricovero e Cura a Carattere Scientifico (CERC-IRCCS), Santa Lucia, Rome, Italy (http://www.hsantalucia.it/neurogen/index_en.htm) for the service provided.

Funding: This study was supported by the Comitato Telethon Fondazione Onlus, the Amministrazione Autonoma dei Monopoli di Stato (AAMS), and the city of Gubbio (Italy; grant no. GGP06209 to A0), the Italian Ministero della Salute (grant nos. EBRI1.0, PS05.21, PS04.20 and RF04.1250 to AO) and the Lundbeck Foundation (Denmark; grant no. COFIN04.1250 to $\mathrm{AO})$.

\section{Competing interests: None declared.}

- Additional references are published online only at http:// jnnp.bmj.com/content/vol79/issue5

Published Online First 30 October 2007
J Neurol Neurosurg Psychiatry 2008;79:606-607. doi:10.1136/jnnp.2007.128827

\section{REFERENCES}

1. Orlacchio A, Patrono C, Orlacchio A, et al. Clinical and genetic studies in hereditary spastic paraplegia. Invited Experts of the Sociedad Iberoamericana de Información Científica (SIIC) En Internet. 2006. available at: http:// www.siicsalud.com/dato/dat051/06d13002.htm (accessed Dec 15, 2006).

2. Hazan J, Fonknechten N, Mavel D, et al. Spastin, a new AAA protein, is altered in the most frequent form of autosomal dominant spastic paraplegia. Nat Genet 1999;23:296-303.

3. Fonknechten N, Mavel D, Byrne P, et al. Spectrum of SPG4 mutations in autosomal dominant spastic paraplegia. Hum Mol Genet 2000;9:637-44.

4. White SR, Evans KJ, Lary J, et al. Recognition of Cterminal amino acids in tubulin by pore loops in Spastin is important for microtubule severing. J Cell Biol 2007; 176:995-1005.

5. Orlacchio A, Kawarai T, Rogaeva E, et al. Clinical and genetic study of a large Italian family linked to SPG12 locus. Neurology 2002;59:1395-402.

\section{Mutations of the SPG11 gene in patients with autosomal} recessive spastic paraparesis and thin corpus callosum

Hereditary spastic paraparesis (HSP) with thin corpus callosum (TCC) is a rare autosomal recessive form of complicated HSP (ARHSP-TCC). The clinical phenotype is characterised by slowly progressive spastic
A

Family 1

I

II

III

IV

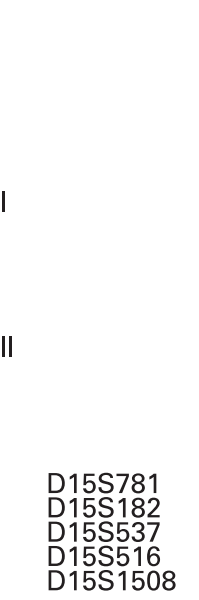

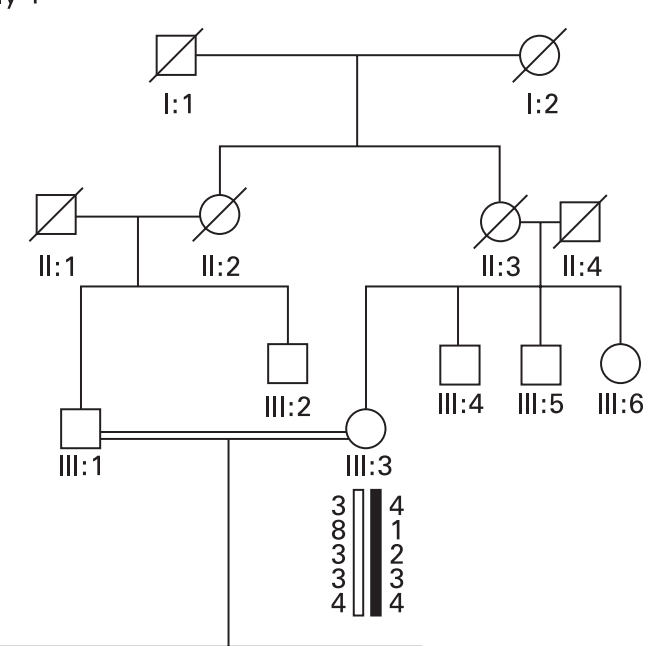

B

Control

IV:3

C CATTHCTTGTCTCTGTGTTTGGATCATCACT T

IV:5
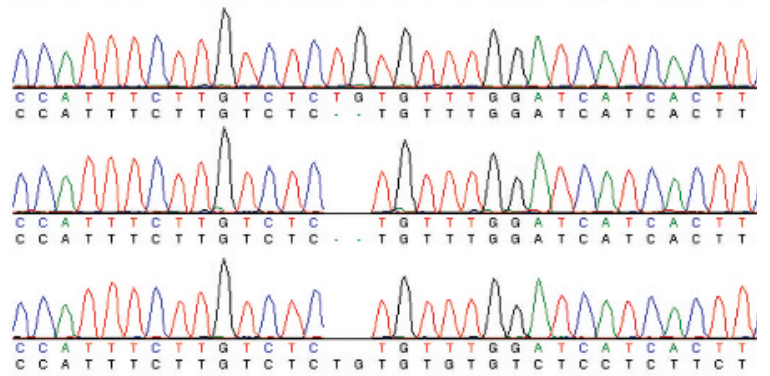

III:3

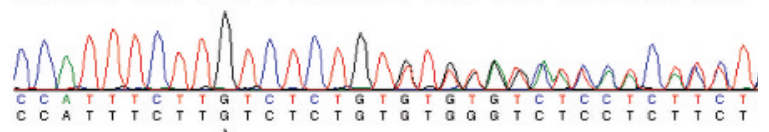

IV:4

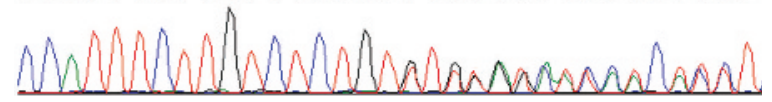

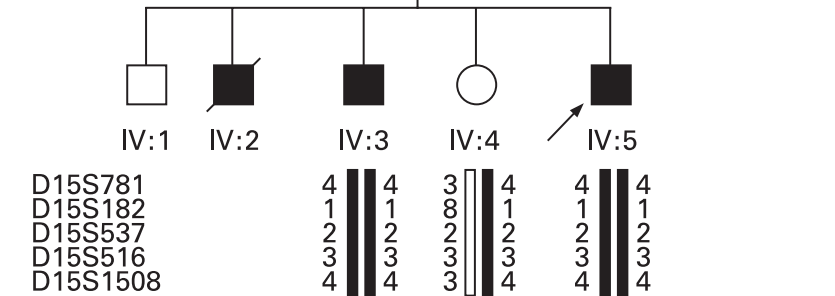

Figure 1 Family pedigree and sequence chromatographs for family No 1. (A) Family No 1 pedigree with genotype data for the five microsatellite marker loci. The solid black bar identifies the likely disease haplotype. (B) Sequence chromatographs for exon 26 of the SPG11 gene in family No 1. The homozygous two nucleotide deletion is clearly defined in the affected individuals (III:3 and III:5) of this pedigree as are the heterozygous status for both the sister (IV:4) and the mother (III:3). 


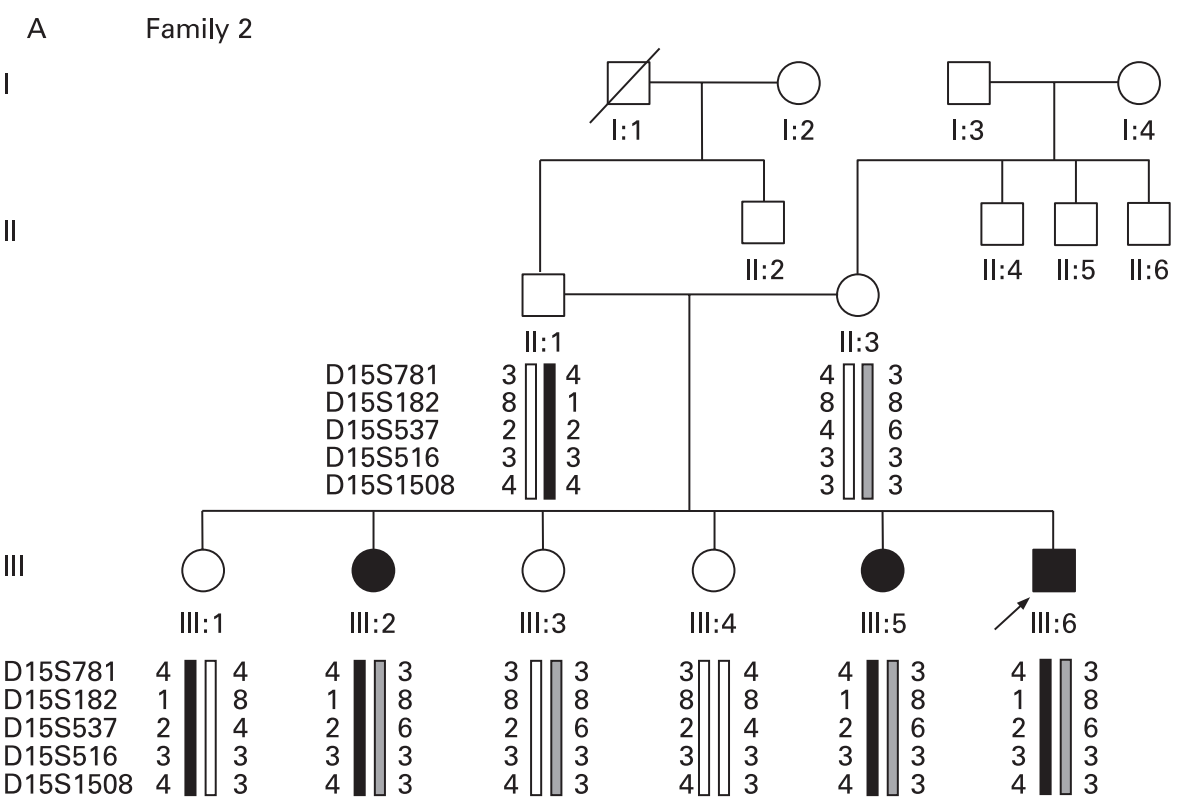

B

Ex. 26

Ex. 32

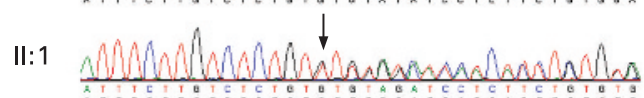

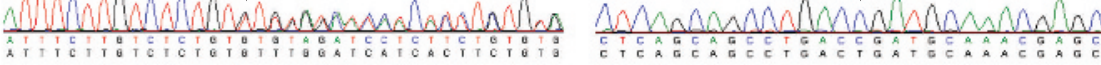

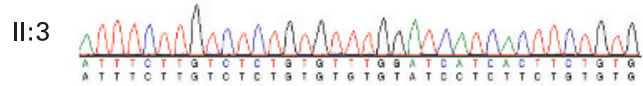

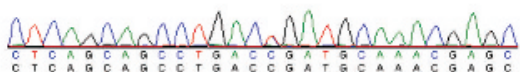

III:1

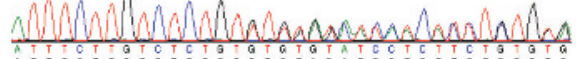

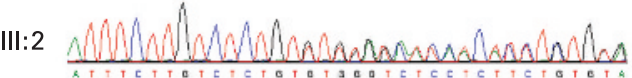

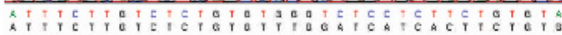

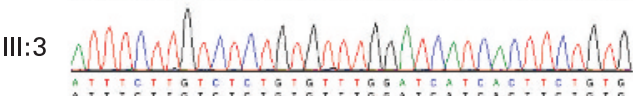

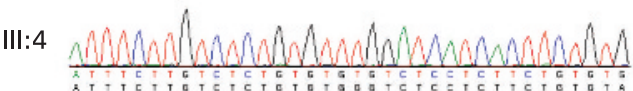

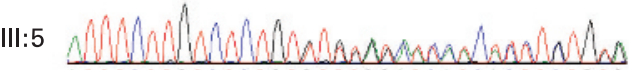

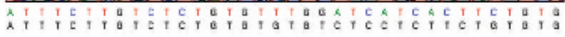

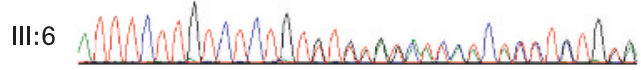
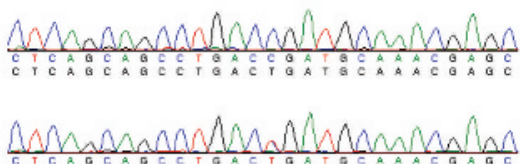

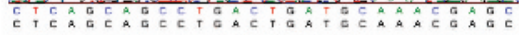
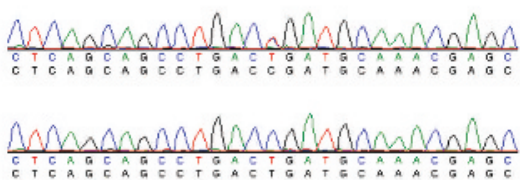

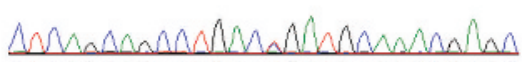

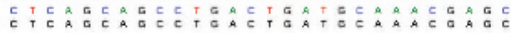

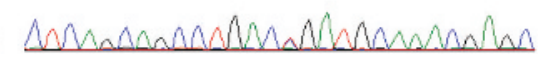

Figure 2 Family pedigree and sequence chromatographs for family No 2. (A) Pedigree and genetic haplotypes data for family No 2. The solid bar identifies the same disease bearing haplotype as that seen in family No 1 while the shaded bar identifies the other disease gene bearing haplotype. (B) Sequence chromatographs of family No 2 identify the carriers of the two nucleotide deletion affecting exon 26 and the $\mathrm{C} \rightarrow \mathrm{T}$ transition in exon 32 . The affected individuals in this pedigree (III:2, III:5 and III:6) carry both mutations (ie, compound heterozygotes) whereas the unaffected individuals carry one or the other of the two mutations.

paraparesis and cognitive impairment which usually occurs during the second decade of life. ${ }^{1}$ However, cognitive impairment is first noticeable during childhood and may precede the occurrence of leg spasticity. The symptoms progress insidiously to severe functional disability over a period of 10 20 years. ${ }^{2}$ Some affected individuals develop a pseudobulbar involvement, with dysarthria, dysphagia and upper limb spasticity. Additional manifestations include urinary incontinence, sensory deficits in the lower limbs and late distal amyotrophy. Seizures, extrapyramidal signs and cerebellar ataxia can occur occasionally. The disorder is found in several ethnic groups, including five Chinese patients with HSP-TCC reported by Tang et al in 2004 . $^{3}$

The SPG11 or KIAA1840 gene, which maps to chromosome $15 \mathrm{q} 21.1{ }^{4}$ was shown to be responsible for ARHSP-TCC when it was demonstrated that individuals with the disease carried mutational changes of SPG11 that segregates with the phenotype within families. ${ }^{5}$ The gene encodes a 2443 amino acid protein, spatacsin, of unknown function.

We provide genetic and phenotypic data on five patients from two Taiwanese/ Chinese families with ARHSP-TCC. Family No 1 has two affected and one unaffected sibs plus an unaffected parent from a consanguineous marriage (fig 1A). Family No 2 has three affected and three unaffected sibs in addition to their parents (fig $2 \mathrm{~A}$ ). Both the index patients (IV:5, family 1 and III:6, family 2) developed a slowly progressive spastic paraparesis in their second decade of life. Initial symptoms, identified by the family, included walking difficulties, straight legs and unsteadiness.

The average age of disease onset for the two families was estimated to be 15.8 (1.9) years (range 13-18 years) (table 1) based on when they first had difficulty walking, as reported by their parents or recorded in their medical records. However, cognitive decline associated with poor performance at school was noted to be at around 11.0 (2.5) years of age. A modified full scale Wechsler Adult Intelligence Scale-III test was used to evaluate cognitive function, verbal skills and full scale intelligence quotient in the five patients. Their performance was markedly reduced compared with control subjects $(<1 \%$ of normal). All five patients suffered from spasticity and hyperreflexia in the lower limbs. Patient III:2 (family No 2) also presented with contracture of the Achilles tendon. Pseudobulbar dysarthria, cerebellar ataxia and distal amyotrophy occurred in some patients. Sphincter problems, especially urinary urgency, frequency and incontinence were common $(4 / 5,80 \%)$. Neurological examination revealed sensory deficits and distal amyotrophy indicative of peripheral neuropathy. Electrophysiological studies revealed a sensorimotor polyneuropathy with axonal loss features in the patients. Ocular cerebellar signs such as square wave jerks and saccadic pursuit were identified in three patients $(3 / 5$, $60 \%$ ). Co-occurrence of generalised seizure was reported in patient III:6, family No 2. Routine MRI brain scans identified the hallmark thinning of the corpus callosum with associated white matter changes $(5 / 5,100 \%)$. Cortical atrophy at the frontal and temporal lobes was prominent compared with the occipital and parietal lobes. Cerebellar atrophy, especially on the vermis, was occasionally found in patients.

Following informed consent, blood samples from each patient and other members of the family were taken for genomic DNA extracted using standard protocols. Individuals were genotyped with microsatellite markers D15S781, D15S182, D15S537, D15S516 and D15S1508 to identify potential linkage to chromosome $15 \mathrm{q} 21.1$ and to establish whether a common haplotype might be present to suggest a common origin for the disease gene. As shown in 
Table 1 Clinical and image findings in five Taiwanese patients with hereditary spastic paraparesis and thin corpus callosum

\begin{tabular}{|c|c|c|c|c|c|}
\hline & \multicolumn{2}{|l|}{ Family No 1} & \multicolumn{3}{|l|}{ Family No 2} \\
\hline & Patient IV:3 & Patient IV:5* & Patient III:2 & Patient III:5 & Patient III:6* \\
\hline \multicolumn{6}{|l|}{ Findings } \\
\hline Sex/age at examination (y) & $\mathrm{M} / 35$ & $\mathrm{M} / 30$ & $F / 34$ & $F / 28$ & $\mathrm{M} / 25$ \\
\hline \multicolumn{6}{|l|}{ Age at onset (y) } \\
\hline Cognitive decline & 12 & 10 & 9 & 15 & 9 \\
\hline Gait disturbance & 16 & 15 & 17 & 18 & 13 \\
\hline \multicolumn{6}{|l|}{ Cognitive function } \\
\hline Verbal IQ & 44 & 45 & 45 & 47 & 48 \\
\hline Performance 10 & 52 & 49 & 46 & 44 & 51 \\
\hline Full scale I0 & 48 & 49 & 47 & 47 & 50 \\
\hline Frontal releasing sign & + & + & + & - & + \\
\hline LL hyperreflexia+spasticity & + & + & + & + & + \\
\hline UL hyperreflexia+spasticity & - & - & + & + & + \\
\hline Extensor plantar response & + & + & C & + & + \\
\hline Pseudobulbar dysarthria & + & + & - & - & + \\
\hline Cerebellar ataxia & + & + & - & - & + \\
\hline Distal amyotrophy & - & - & + & + & - \\
\hline Urinary dysfunction & - & $\begin{array}{l}\text { Frequency + } \\
\text { incontinence }\end{array}$ & Incontinence & Frequency & Frequency \\
\hline \multicolumn{6}{|l|}{ Brain MRI } \\
\hline Age at scan (y) & 35 & 30 & 34 & 29 & 25 \\
\hline Thin corpus callosum & All & All & All & $\begin{array}{l}\text { All (nearly } \\
\text { absent) }\end{array}$ & All \\
\hline White matter change & $\mathrm{F}, \mathrm{Pv}$ & $\mathrm{F}, \mathrm{Pv}$ & $\mathrm{F}, \mathrm{Pv}$ & $\mathrm{F}, \mathrm{Pv}$ & $\mathrm{F}, \mathrm{Pv}$ \\
\hline Cortical atrophy & $\mathrm{F}, \mathrm{T}$ & $\mathrm{F}, \mathrm{T}$ & $\mathrm{F}, \mathrm{T}$ & $\mathrm{F}$ & $\mathrm{F}, \mathrm{T}$ \\
\hline Cerebellar atrophy & + & + & + & - & + \\
\hline \multicolumn{6}{|l|}{ Tibial nerve, right } \\
\hline $\operatorname{MNCV}(\mathrm{m} / \mathrm{s})$ & 45 & ND & Absent & 34 & 38 \\
\hline CMAP (mV) & 8.4 & ND & Absent & 6.0 & 7.1 \\
\hline \multicolumn{6}{|l|}{ Sural nerve, right } \\
\hline $\operatorname{SNCV}(\mathrm{m} / \mathrm{s})$ & 47 & ND & 37 & 40 & 39 \\
\hline $\operatorname{SAP}(\mu \mathrm{V})$ & 5.0 & ND & 4.2 & 13.8 & 14.3 \\
\hline EMG & Giant MUP & ND & NPW & $\begin{array}{l}\text { Spontaneous } \\
\text { activities }\end{array}$ & $\begin{array}{l}\text { Giant MUP, } \\
\text { NPW. }\end{array}$ \\
\hline Other features & $\begin{array}{l}\text { Square wave } \\
\text { jerks, saccadic } \\
\text { pursuit }\end{array}$ & Saccadic pursuit & & & $\begin{array}{l}\text { Saccadic } \\
\text { pursuit, } \\
\text { generalised } \\
\text { epilepsy }\end{array}$ \\
\hline
\end{tabular}

All, all parts of the corpus callosum; $C$, contracture of Achilles tendon; CMAP, compound muscle action potential; $F$, frontal; LL, lower limb; MNCV, motor nerve conduction velocity; MUP, motor unit potential; ND, not done; NPW, neurogenic polyphasic waves; $\mathrm{PV}$ periventricular; SAP, sensory action potential; SNCV, sensory nerve conduction velocity; T, temporal; UL, upper limb.

${ }^{*}$, proband; +, presence; -, absence.

fig $1 \mathrm{~A}$, the affected members (patients IV:3 and IV:5) from the consanguineous marriage (family No 1) were homozygous for the five microsatellite markers surrounding the SPG11 gene. The unaffected sib (IV:4) and parent (III:3) carried the heterozygous allele at these loci. These data are suggestive that the disease gene probably segregates with the homozygous genotype. In family No 2 (fig 2A), affected family members (III:2, III:5 and III:6) shared a common genotype that was not present in unaffected members (II:1, II:3, III:1, III:3 and III:4). Furthermore, the affected individuals carry a haplotype (41234) that is also present in affected members from family No 1. Again the data are not inconsistent with linkage of the disease gene to this region of the genome.

BigDye Terminator chemistry (Applied Biosystems, Foster City, California, USA) and an ABI3100 automatic DNA sequencer was used to analyse the sequence of all 40 exons of the SPG11 gene in the two families. This analysis identified a two nucleotide deletion in exon 26 (c.4461..4462delGT) affecting both families (fig 1B, 2B) which is predicted to cause a frameshift ( $p$. Cys1487fs) mutation leading to a truncated protein. In family No 1, involving a consanguineous marriage, the affected children (IV:3 and IV:5) were homozygous for the two nucleotide deletion whereas the unaffected child (IV:4) and parent (III:3) were heterozygous. Both affected (III:2, III:5 and III:6) and unaffected (II:1 and III:1) individuals in family No 2 were heterozygous for the two nucleotide deletion in exon 26. However, a $\mathrm{C} \rightarrow \mathrm{T}$ transition in exon 32 at nucleotide 6091 was also detected in this family (fig 2B) which is predicted to introduce a premature stop codon at arginine 2031. Both affected (III:2, IIII:5 and III:6) and unaffected (II:3 and III:3) were heterozygous for this change. However, only the affected individuals carried both mutations. Neither change was observed in a 150 Taiwanese controls samples.

By following the segregation of the two SPG11 alleles through the pedigree in family No 2, it appears that the two nucleotide deletion segregates with the 41234 haplotype which is the homozygous haplotype of the affected individuals in family No 1 . This would suggest that the deletion mutation has a common origin in the two families.

To date, 30 ARHSP-TCC families worldwide have been identified with genetic linkage to SPG11. Thus far, the only SPG11 gene mutations to be described come from families around the Mediterranean Sea. ${ }^{5}$ Thus our characterisation of two Taiwanese families with SPG11 gene mutations provides additional corroboration that the SPG11 is the responsible gene for ARHSP-TCC.

M-J Lee, ${ }^{1,2}$ T-W Cheng, ${ }^{1}$ M-S Hua, ${ }^{3}$ M-K Pan, ${ }^{1} \mathrm{~J}$ Wang, ${ }^{2}$ D A Stephenson, ${ }^{4}$ C-C Yang ${ }^{1}$

${ }^{1}$ Department of Neurology, National Taiwan University School of Medicine, Taipei, Taiwan; ${ }^{2}$ Medical Genetics, National Taiwan University School of Medicine, Taipei, Taiwan; ${ }^{3}$ Department of Psychology, National Taiwan University, Taipei, Taiwan; ${ }^{4}$ Pharmacology Department, School of Pharmacy, Brunswick Square, London, UK

Correspondence to: Dr C-C Yang, Department of Neurology, National Taiwan University Hospital, 7 ChungShan South Road, Taipei 100, Taiwan; jesse@ ha.mc.ntu.edu.tw

\section{Competing interests: None.}

J Neurol Neurosurg Psychiatry 2008;79:607-609. doi:10.1136/jnnp.2007.136390

\section{REFERENCES}

1. Ueda M, Katayama Y, Kamiya T, et al. Hereditary spastic paraplegia with a thin corpus callosum and thalamic involvement in Japan. Neurology 1998;51:1751-4.

2. Nakamura A, Izumi K, Umehara F, et al. Familial spastic paraplegia with mental impairment and thin corpus callosum. J Neurol Sci 1995;131:35-42.

3. Tang BS, Chen X, Zhao GH, et al. Clinical features of hereditary spastic paraplegia with thin corpus callosum: report of 5 Chinese cases. Chin Med J (Engl) 2004;117:1002-5.

4. Martinez MF, Kobayashi H, Pegoraro E, et al. Genetic localization of a new locus for recessive familial spastic paraparesis to 15q13-15. Neurology 1999;53:50-6.

5. Stevanin G, Santorelli FM, Azzedine H, et al. Mutations in SPG11, encoding spatacsin, are a major cause of spastic paraplegia with thin corpus callosum. Nat Genet 2007;39:366-72.

6. Del BR, Di FA, Ghezzi S, et al. SPG11: a consistent clinical phenotype in a family with homozygous Spatacsin truncating mutation. Neurogenetics 2007;8:301-5.

\section{Relapsing polychondritis: an uncommon cause of dementia}

Relapsing polychondritis (RP) is a rare disorder that is characterised by recurrent and progressive inflammation of cartilaginous structures. ${ }^{1}$ Nervous system involvement in RP has been described. ${ }^{1-5} \mathrm{We}$ describe two cases of RP with subacute dementia. 